\title{
Predictive phytotoxic value of water-soluble allelochemicals in plant extracts for choosing a cover crop or mulch for specific weed control
}

\author{
Carolina G. Puig, ${ }^{1,2}$ Francisco Valencia-Gredilla, ${ }^{3}$ María Pardo-Muras, ${ }^{1,2}$ X. Carlos Souto, ${ }^{4}$ \\ Jordi Recasens, ${ }^{3}$ Nuria Pedrol ${ }^{1,2}$ \\ ${ }^{1}$ Department of Plant Biology and Soil Science, University of Vigo, Vigo; ${ }^{2}$ CITACA, Agri-Food Research \\ and Transfer Cluster, Campus da Auga, University of Vigo, Ourense; ${ }^{3}$ Department of Horticulture, Botany \\ and Landscaping, Agrotecnio CERCA center, University of Lleida, Lleida; ${ }^{4}$ EUET Forestal, University of \\ Vigo, University Campus, Pontevedra, Spain
}

\section{Highlights}

- The phytotoxic nature of the aqueous extracts of twelve conventional and novel cover crops and mulch species was demonstrated in vineyards' three troublesome weed species.

- Phenolic acids and flavonoids of the twelve aqueous extracts were identified and quantified by HPLC-DAD, and, by regression analysis, some allelochemicals were postulated as responsible for the phytotoxic effects.

- The water-soluble phenolic profiles of three potential cover crops, namely Hordeum murinum, Vulpia ciliata, and Medicago rugosa, are reported for the first time.

- In vitro germination and early root growth of Conyza bonariensis and Aster squamatus were almost entirely restricted by any of the twelve plants' aqueous extracts and presumably by the joint action of their particular allelopathic compounds.

- Bassia scoparia germination was relatively much less sensitive to the extracts, except for Trifolium subterraneum, for which the flavonoid naringenin was predicted to underlie its specific phytotoxicity.

\begin{abstract}
Cover crops and mulches have become an alternative for soil management in vineyards due to the agronomic, environmental, and economic advantages, especially the possibility of weed
\end{abstract}

\footnotetext{
Correspondence: Nuria Pedrol, Department of Plant Biology and Soil Science, University of Vigo, Campus As Lagoas-Marcosende, 36310 Vigo, Spain. E-mail: pedrol@uvigo.es

Key words: Allelopathy; bioassays; bioherbicides; flavonoids; organic agriculture; phenolic acids; phytotoxicity; vineyards.

Acknowledgements and funding: this work was funded by the Spanish Ministry of Economy and Competitiveness (AGL2014-52465-C4-2-R and AGL2017-83325-C4-2-R) and by the Centre for Technological and Industrial Development (CDTI). The second author obtained a PhD grant from the University of Lleida.
}

Received for publication: 15 March 2021.

Revision received: 9 July 2021.

Accepted for publication: 9 July 2021.

(C) Copyright: the Author(s), 2021

Licensee PAGEPress, Italy

Italian Journal of Agronomy 2021; 16:1872

doi:10.4081/ija.2021.1872

This article is distributed under the terms of the Creative Commons Attribution Noncommercial License (by-nc 4.0) which permits any noncommercial use, distribution, and reproduction in any medium, provided the original author(s) and source are credited. control. Implicitly to this objective lies the idea of assessing the potential herbicide effect of the allelochemicals released by different cover crops and mulch species. With this objective, the present work evaluated the phytotoxic effects of 12 aqueous extracts of selected species with potential use as a cover crop or mulch: a Bromus species mixture (B. hordeaceus L. and B. rubens L.), Festuca arundinacea Schreb., Hordeum murinum L., $H$. vulgare L., Vulpia ciliata Dumort., Medicago rugosa Desr., M. sativa L., Trifolium subterraneum L., T. incarnatum L., Phacelia tanacetifolia Benth., Sinapis alba L., and Pinus sylvestris L., on the germination and early growth of three troublesome weeds (Conyza bonariensis (L.) Cronquist, Aster squamatus (Spreng.) Hieron, and Bassia scoparia (L.) A. J.). The different in vitro bioassays showed that aqueous extracts of some species significantly inhibited or reduced germination and root and shoot growth of the target weed species in a dose-response manner. Germination of $A$. squamatus and $C$. bonariensis was reduced by $100-80 \%$ by the different extracts applied at $50 \%$ concentration and completely blocked at $100 \%$ concentration, except for $M$. rugosa extract, to which both species showed less sensitivity. Root elongation of $A$. squamatus was inhibited under every extract and concentration, whereas $C$. bonariensis root growth showed only some tolerance to the crude extracts of $F$. arundinacea and $P$. sylvestris. Bassia scoparia was relatively tolerant to the aqueous plant extracts, except for T. subterraneum crude extract, which reduced total germination by $80 \%$; otherwise, B. scoparia showed higher general sensitivity of shoot growth than the other two weed species.

The chemical profiles of phenolic compounds of the aqueous extracts were obtained and identified by HPLC-DAD, the phenolic profiles of $H$. murinum, $V$. ciliata, and $M$. rugosa being reported in this work for the first time. Using stepwise regression, the influence of certain phenolic compounds from the aqueous extracts on the 
germination and early growth of weeds was predicted. Among other significant compounds, the flavonoid naringenin identified in $T$. subterraneum aqueous extract at $8.09 \mu \mathrm{g} \cdot \mathrm{mL}^{-1}$ was predicted to underlie its specific phytotoxicity on $B$. scoparia germination. These results support the use of cover crops and mulches in weed management and can help to select the most suitable species to adopt according to the target weed species.

\section{Introduction}

Different factors, including weed presence, can compromise grape production. Weeds' high competition for water and nutrients (Oerke, 2006) makes weed management a fundamental challenge in viticulture, where the presence of herbicide-resistant biotypes is worryingly increasing (Heap, 2021). For weed control, winegrowers usually till and/or apply herbicides, but these managements have a series of disadvantages, such as erosion, land contamination, or the mentioned evolution of herbicide resistance, among others (Cerdan et al., 2010; Prosdocimi et al., 2016; Heap, 2021). An alternative is establishing a cover crop or mulching, suitable for both organic and conventional vineyards with continuous inter-row use. The use of cover crops and mulches in Mediterranean vineyards is identified as a good ecosystem service for the sustainability of the production system. Cover crops bring several advantages from an agronomic, environmental, or economic point of view (Morlat and Jacquet, 2003; Gómez et al., 2011; Ibáñez, 2015; Warren et al., 2021), being weed suppression one of them (Álvarez-Iglesias et al., 2018; Garcia et al., 2018; Abad et al., 2020).

Apart from their benefits preventing soil erosion and compaction, cover crops can reduce weed presence for the competition exerted for light, water, and nutrients. However, they can also release a cocktail of secondary metabolites (allelochemicals) that spread into the soil by leaching and volatilization and reach the recipient weed seeds, interfering with their development (Weston and Duke, 2003; Farooq et al., 2011; Sturm et al., 2018; Puig et al., 2019). Many of the allelochemicals secreted from plant species are soluble in water, phenolic compounds being the main phytotoxins present in the aqueous extracts (Li et al., 2010). Phenolic compounds have been widely reported to affect physiological processes such as germination, growth, plant water balance, phytohormone activity, photosynthesis, respiration, and synthesis of certain compounds (Einhellig, 2004; Li et al., 2010).

Previous studies reported some effectiveness in suppressing weeds for a variety of organic mulches established in vineyards, like Festuca arundinacea Schreb., Hordeum vulgare L., Medicago rugosa Desr., M. sativa L., Trifolium subterraneum L., T. incarnatum L., Phacelia tanacetifolia Benth., Sinapis alba L., and Pinus sylvestris L. (e.g., Fujii, 2001; Bulut and Demir, 2007; Tursun et al., 2018). However, the phytotoxic potential of the aqueous extracts of some of these cover crops and other species under consideration like Bromus rubens L., H. murinum L., and Vulpia ciliata Dumort have not been thoroughly studied to date.

The efficacy and magnitude of the allelopathic effect depend on the installed cover crop and the target weeds to be controlled (Kunz et al., 2016; Álvarez-Iglesias et al., 2018). Some weeds, including those assayed here: Aster squamatus (Spreng.) Hieron, Bassia scoparia (L.) A. J. and Conyza bonariensis (L.) Cronquist have become hard to manage in vines and other crops due to their biological characteristics. Aster squamatus is a species native to central South America and widely distributed in many European countries (Sajna et al., 2014). This species is difficult to control in vineyards and orchards in Spain due to its adaptation to mechanical shredding (Recasens et al., 2018), its high fecundity, and its airborne dispersion (Sajna et al., 2014). Besides, the presence of resistant biotypes to three imidazolinone herbicides along with crossresistance to sulfonylurea herbicides has been confirmed in Spain (Osuna et al., 2003). Bassia scoparia is also a noxious weed in vineyards (Recasens et al., 2018), displaying an effective seed dispersal mechanism by tumbleweeds with high potential fecundity (Osipitan, 2016; Osipitan et al., 2019). Chemical weed control in vineyards is not easy, which can be explained by different factors: in general, herbicide effectiveness is reduced as plant size increases, and B. scoparia shows rapid growth (Friesen et al., 2009). Furthermore, this species presents difficult-to-wet leaf characteristics (such as pubescent leaves), reducing herbicide absorption and decreasing herbicide efficacy (Friesen et al., 2009). Bassia scoparia is resistant to several herbicides, and some biotypes have developed multiple resistance (in some cases, four sites of action) (Heap, 2021). Conyza bonariensis is also difficult to control (Bajwa et al., 2016), with high fecundity and efficient airborne dispersion of seeds (Kempen \& Graf, 1981; Savage et al., 2014). Herbicide effectiveness depends on both the growing plant stage and if the biotype is herbicide-resistant. Conyza bonariensis has been confirmed for its multiple resistances to herbicides with different action sites (Heap, 2021). In Spain, populations of $C$. bonariensis sampled from perennial crop locations have been confirmed simazine-resistant (De Prado et al., 1989) and glyphosate-resistant (Urbano et al., 2007).

After the evidence of harm caused by these weeds and the difficulty of controlling them by mechanical or chemical methods, the need to develop alternative strategies that inhibit seed germination and emergence has arisen. In this context, studying the phytotoxic effect of different aqueous extracts of species used as a living cover crop or mulch in vineyards is promising. In order to isolate the experiment from the effect of biotic and abiotic factors, in vitro assays under controlled conditions were carried out to evaluate the phytotoxic potential of the aqueous extracts of 12 different species to be used as a living cover crop or mulch in vineyards, on the germination and root and shoot growth of three noxious weeds: C. bonariensis, A. squamatus and B. scoparia. According to these trials, complementary analyses of the chemical profiles of water-soluble compounds (phenolic acids and flavonoids) were carried out. Finally, the phenolic compounds potentially involved in the aqueous extracts' observed phytotoxicity were statistically predicted.

\section{Materials and methods}

\section{Plant material}

Different species to be used as a cover crop and/or mulch in vineyards were selected for the experiment: a Bromus mixture ( $B$. hordeaceus and B. rubens), F. arundinacea cv. 'Firaces R1', $H$. murinum, H. vulgare cv. 'Meseta', V. ciliata, M. rugosa. cv. 'Sapo', M. sativa cv. 'Victoria', T. incarnatum cv. 'Red', T. subterraneum cv. 'Dalkeith', P. tanacetifolia, S. alba, and P. sylvestris. Most species were sown in experimental fields of the University of Lleida (Lleida, Spain) in autumn (November 2016) and collected in spring (April-May 2017) when legume-species were at flowering stage and gramineous had started spike development. Specifically, the harvest date for each cover crop was: 03/31/17 for M. rugosa, S. alba and 
H. murinum; 04/04/17 for $T$. subterraneum and $V$. ciliata; 04/05/17 for Bromus sp. and T. incarnatum; 04/19/17 for F. arundinacea and H. vulgare; $04 / 26 / 17$ for $M$. sativa; and $05 / 29 / 17$ for $P$. tanacetifolia. Entire plants, including flowers, leaves, and roots, were collected. In the case of $P$. sylvestris (collected on $05 / 02 / 17$ ), only new branches $\leq 25 \mathrm{~cm}$ in length were considered. The plant materials were dried at $20^{\circ} \mathrm{C}$ in semi-darkness in the laboratory until constant weight. Then, the dry material was packed until the bioassays.

Seeds of the target weed species C. bonariensis, A. squamatus, and $B$. scoparia were collected in a commercial organic vineyard in Raimat (4139'29'N, 0³1'26'"E) (Lleida, Spain) from different plants throughout the field in September 2016. Then, seeds were air-dried under laboratory conditions and stored in the dark in paper bags.

\section{Plant aqueous extracts}

In July 2017, the plant materials were processed at the laboratory of Plant Ecophysiology of the University of Vigo. Each plant material was slashed into $1 \mathrm{~cm}^{2}$-sized pieces and mixed thoroughly. For each species, plant material was placed in a $2-\mathrm{L}$ Erlenmeyer flask at a plant dry weight/distilled water volume ratio of $66.7 \mathrm{~g} \mathrm{~L}^{-1}$ (Puig et al., 2018; Pardo-Muras et al., 2020). Erlenmeyer flasks were left in a dark room at environmental temperature for $24 \mathrm{~h}$ and soaked every 6 hours. The obtained aqueous extracts were vacuum filtered through $45 \mu \mathrm{m}$ cellulose membrane to clean impurities and then through $0.45 \mu \mathrm{m}$ to avoid contamination by microorganisms. Then, all extracts were frozen at $-20^{\circ} \mathrm{C}$ in aliquots in sterile plastic bottles. Fifteen $\mathrm{mL}$ of each frozen aqueous extract was freeze-dried in a lyophilizer (Telstar CRYODOS) until the chemical analyses.

\section{Phytotoxicity dose-response bioassays of the aqueous extracts}

The crude extract was diluted in distilled water at 100, 50, and $0 \%(\mathrm{v} / \mathrm{v})$ for each species, corresponding to concentrations of 66.7 , 33.3 , and $0 \mathrm{~g} \mathrm{dw} \mathrm{L}^{-1}$, respectively. In addition, values for osmolarity (Gonotec OSMOMAT 030 cryoscopic osmometer), electrical conductivity (EC, Crison CDTM-523 conductivity meter), and $\mathrm{pH}$ (Crison MicropH 2001 pHmeter) were measured for each solution.

Seeds of the different weed species were surface-sterilized as Kruidhof et al. (2014) described by shaking the seeds for $5 \mathrm{~min}$ in a $0.5 \%$ bleach solution and then rinsing them for 2 min with deionized water.

For in vitro germination bioassays, weed seeds were incubated in 6-well plates at the rate of 15 seeds per well placed on a layer of filter paper wetted with $600 \mu \mathrm{L}$ of solution. For each target weed species, aqueous extract, and concentration, six replicates were placed. Seeds were incubated in growth chambers at different temperatures: $30 / 20^{\circ} \mathrm{C}$ for $C$. bonariensis and $B$. scoparia and $15 / 5^{\circ} \mathrm{C}$ for $A$. squamatus with a $12 / 12 \mathrm{~h}$ day/night photoperiod, based on literature review for their optimal germination temperatures (Wu et al., 2007; Al-Alahmadi and Mohammad, 2007) besides trial-and-error adjustment. Germinated seeds were counted every $12 \mathrm{~h}$ for $B$. scoparia and every $24 \mathrm{~h}$ for $C$. bonariensis and $A$. squamatus until no new germination events were observed in control seeds on five consecutive days. A seed was considered germinated when the root exceeded $1 \mathrm{~mm}$ in length (Mayer and Poljakoff-Mayber, 1963).

For in vitro early growth bioassays, ten pre-germinated seeds of each target weed species (1 mm root length) were placed in a Petri dish of $9 \mathrm{~cm}$ diameter on a layer of filter paper wetted with 4 $\mathrm{mL}$ of solution and incubated under the same conditions described for germination bioassays. For each target weed species, aqueous extract, and concentration, four replicates were placed. After 48 hours of incubation, root and shoot lengths were measured.

\section{Quantification and identification of phenolic com- pounds from the cover crops aqueous extracts}

The analysis and characterization of each species' phenolic compounds were performed following the methodology described by Souto et al. (2001).

\section{Extraction procedure}

The lyophilized aqueous extracts were re-dissolved in $15 \mathrm{~mL}$ of distilled water. Afterward, three sequential extractions with $15 \mathrm{~mL}$ of diethyl ether were performed. First, the mixture was extracted with an extraction funnel by shaking vigorously for one minute each time, waiting until the complete separation of two phases: the aqueous one in the lower part and the organic one in the upper part of the funnel containing the ether extracted phenolics. Next, the organic phase was removed and saved, collecting the three ethereal phases (approximately $45 \mathrm{~mL}$ ) to an Erlenmeyer flask. Another three sequential extractions with $15 \mathrm{~mL}$ of ethyl acetate on the aqueous phase were then performed, obtaining three new organic phases that were collected and combined with the ethereal ones. Subsequently, the total organic fraction was evaporated to dryness in the rotary evaporator. The final residue containing the phenolics was reconstituted in $1 \mathrm{~mL}$ of methanol.

\section{HPLC analysis}

The analysis was performed using an HPLC (Shimadzu chromatograph) equipped with a UV-DIODE ARRAY detector to identify flavonoids and phenolic acids. Using a reverse-phase Waters Nova-Pak C-18 $(4.6 \times 250 \mathrm{~mm})$ column with a $4 \mu \mathrm{m}$ particle size, identification was achieved.

The extracts were analysed using two mobile phases for flavonoids analysis: Solvent A was $0.1 \%$ phosphoric acid in methanol; solvent B was $0.1 \%$ phosphoric acid in pure water. HPLC grade solvents were used. Linear gradients starting at 20\% (A) and ending at $100 \%(\mathrm{~A})$ were used over the first $50 \mathrm{~min}$., plus $5 \mathrm{~min}$ at $100 \%$ (A). The mobile phase's flow rate was $1 \mathrm{~mL} / \mathrm{min}$, and the eluate was analysed at 250-400 nm (Hussain et al., 2011).

For phenolic acids, linear gradient elution was carried out at a flow rate of $1.5 \mathrm{~mL} / \mathrm{min}$. Solvent A was $0.5 \%$ acetic acid in pure water, and solvent $\mathrm{B}$, acetonitrile with $0.5 \%$ acetic acid. The gradient from $0 \%$ to $20 \%$ B over $45 \mathrm{~min}$ was followed by $15 \mathrm{~min}$ re-equilibration with $\mathrm{A}$. The eluate was analysed at 210-400 $\mathrm{nm}$.

Identification and quantification of both flavonoids and phenolic acids were performed by comparing retention times, wavelength detection, and peak areas to those of standard compounds. In addition, derivative compounds were quantified using peak areas of the correspondent aglycones.

\section{Statistical analyses}

The replicated experiment was performed and followed in a completely randomized design. The obtained values were expressed as a percentage of the respective control. All data were tested for normality and homogeneity by Kolmogorov-Smirnov and Levene's test. Differences between each treatment and the control were tested by independent samples Student's t-test $(\mathrm{P}=0.05)$. One-way ANOVA tested differences between treatments, and means were compared by the Waller-Duncan test at $\mathrm{P} \leq 0.05$ in case of normality and homoscedasticity. When heteroscedastic, data were subjected to Kruskal-Wallis $H$ test and post hoc Tamhane's $T 2$ test at $\mathrm{P} \leq 0.05$.

Stepwise regression analyses 'forwards' were carried out on the 
results of a linear model to determine which phenolic compounds in the aqueous extracts of the different plants best explained the effects on the germination and early growth of the target weed species. Predictor variables were only entered into the stepwise regression if hierarchical partitioning analysis revealed an independent effect $\geq 5 \%$. As a result, the stepwise regression displayed a final model explaining a high percentage of the variance, with fewer predictive variables than the initial model.

All statistical analyses were performed with the IBM SPSS Statistics 19.0 software package (IBM SPSS Inc., Chicago, IL, USA), and graphs were conducted with SigmaPlot 11.0 (Systat Software, San Jose, CA, USA).

\section{Results}

\section{pH, EC, and osmolarity values}

Values of $\mathrm{pH}, \mathrm{EC}$, and osmolarity of the plant extracts ranged from 4.43 to 7.02 , from 0.43 to $7.93 \mathrm{dS} \mathrm{m}^{-1}$, and from 0.018 to 0.208 osmol kg-1, respectively (Table 1).

\section{Dose-response bioassays of the aqueous extracts}

The high germination percentage of control treatments revealed the suitability of the conditions to which seeds were subjected as well as the viability of them, with germination values of $92.2 \pm 12 \%$ for C. bonariensis, $85 \pm 14.2 \%$ for $A$. squamatus, and $98.3 \pm 1.2 \%$ for B. scoparia (mean \pm standard deviation).

Aqueous extracts from the different species selected as a cover crop and/or mulch produced phytotoxic effects on the three assayed target weed species in a dose-response manner, both in terms of germination or/and root and shoot elongation.

The effects of the aqueous extracts on the germination and growth of $C$. bonariensis are represented in Figure 1. All of the assayed aqueous extracts significantly reduced this species' germination percentage. Germination was entirely inhibited by six species (Bromus sp., F. arundinacea, H. murinum, H. vulgare, $M$. sativa, and T. incarnatum) at both doses $(\mathrm{P} \leq 0.001)$. The other plant extracts also inhibited C. bonariensis germination at $100 \%$ dose, except M. rugosa, for which a value of about $15 \%$ of total germination was obtained. At $50 \%$ dose for $S$. alba, P. sylvestris, $T$. subterraneum, V. ciliata, and P. tanacetifolia, the percentage of germinated seeds ranged from $4 \%$ to $20 \%$ compared to control. Conyza bonariensis root growth was also significantly inhibited by the different aqueous extracts and doses, except $P$. sylvestris at $50 \%$ (Figure1B). Extracts from seven of the twelve assayed species (Bromus mixture, H. murinum, H. vulgare, M. rugosa, T. incarnatum, $P$. tanacetifolia, and $S$. alba) completely blocked root elongation at both doses. Regarding the extracts of $M$. sativa and $T$. subterraneum, whereas the root length values were $4 \%$ and $14 \%$, respectively, at $50 \%$ dose, the root growth was entirely inhibited at $100 \%$ dose. Vulpia ciliata at 50\% dose, and P. sylvestris and F. arundinacea at $100 \%$ dose also reduced root elongation significantly, with $62 \%, 21 \%$, and $6.5 \%$, respectively. In the case of shoot growth (Figure 1C), almost all aqueous extracts at both doses significantly stimulated the shoot length of $C$. bonariensis or resulted in neutral. However, the extracts of $H$. murinum (at $100 \%$ dose) and $P$. sylvestris (at 50\% dose) significantly restricted shoot elongation by $17 \%$ and $32 \%$ compared to control, respectively.

Effects of the aqueous extracts on the germination and growth of A. squamatus are displayed in Figure 2. All plant extracts had a highly significant inhibitory effect on seed germination $(\mathrm{P} \leq 0.001)$. Those extracts from Bromus mixture, F. arundinacea, H. murinum, M. sativa, T. incarnate, P. tanacetifolia, and P. sylvestris completely inhibited germination at both doses (Figure 2A). At 100\% dose, all species impeded seed germination except M. rugosa, where 5\% of total germination was obtained. At $50 \%$ dose, the germination percentages were variable, with values between $40 \%$ for $M$. rugosa and $11 \%$ for $V$. ciliata. Root elongation was deterred by the effect of all assayed extracts and concentrations (Figure 2B). Shoot elongation was significantly reduced $(\mathrm{P} \leq 0.001)$ by all aqueous extracts at both doses compared to control, except for $50 \%$ of $M$. sativa and T. subterraneum, with no differences with control (Figure 2C). The lowest shoot length values were observed for the extract of P. tanacetifolia at $100 \%$ and $50 \%$ doses, with $26 \%$ and $40 \%$, respectively. The other extracts showed final values of shoot length ranging between $48 \%$ for $H$. murinum and $T$. incarnatum and $83 \%$ for $V$. ciliata, at doses of $50 \%$ in all cases.

The phytotoxic effects of the aqueous extracts from the species tested on the germination and growth of $B$. scoparia are represented in Figure 3. Trifolium subterraneum was the species that exerted

Table 1. Physicochemical properties of the aqueous plant extracts at two different concentrations: $\mathrm{pH}$, electrical conductivity $\left(\mathrm{dS} \cdot \mathrm{m}^{-1}\right)$, and osmolarity $\left(\right.$ osmol. $\left.\mathrm{kg}^{-1}\right)$.

\begin{tabular}{|c|c|c|c|c|c|c|}
\hline & & & & & & \\
\hline & $50 \%$ & $100 \%$ & $50 \%$ & $100 \%$ & $50 \%$ & $100 \%$ \\
\hline Bromus mixture & 4.60 & 4.59 & 2.03 & 3.60 & 0.070 & 0.140 \\
\hline Festuca arundinacea & 4.86 & 4.84 & 1.58 & 2.80 & - & - \\
\hline Hordeum murinum & 4.47 & 4.43 & 2.03 & 3.14 & 0.075 & 0.158 \\
\hline Hordeum vulgare & 5.66 & 5.70 & 2.13 & 3.57 & 0.091 & 0.162 \\
\hline Vulpia ciliata & 5.71 & 5.72 & 1.40 & 2.53 & 0.051 & 0.102 \\
\hline Medicago rugosa & 7.02 & 6.61 & 1.83 & 3.06 & 0.093 & 0.176 \\
\hline Medicago sativa & 6.30 & 6.16 & 1.18 & 2.16 & - & - \\
\hline Trifolium incarnatum & 4.72 & 4.68 & 2.50 & 4.15 & 0.113 & 0.208 \\
\hline Trifolium subterraneum & 6.30 & 6.44 & 1.75 & 2.93 & 0.081 & 0.145 \\
\hline Phacelia tanacetifolia & 6.02 & 5.91 & 1.85 & 3.22 & 0.067 & 0.130 \\
\hline Sinapis alba & 6.40 & 6.17 & 1.90 & 7.93 & 0.073 & - \\
\hline Pinus sylvestris & 5.24 & 5.13 & 0.43 & 0.81 & 0.018 & 0.035 \\
\hline
\end{tabular}

(-) Absent values due to the high viscosity of the sample. 
more phytotoxic effect, significantly different from the rest of the species, and with final values of $44 \%$ and $23 \%$ of germination for 50 or $100 \%$ doses, respectively. The other species significantly restricted the final germination with values ranging from $65 \%$ for H. murinum to $94 \%$ for H. vulgare. Festuca arundinacea and $T$. incarnatum at both doses, and H. vulgare, V. ciliata, and $S$. alba at $50 \%$ resulted innocuous for B. scoparia germination (Figure 3A). Root elongation was significantly inhibited by all the extracts and doses $(\mathrm{P} \leq 0.001)$ with values lower than $50 \%$ compared to the control (Figure 3B). Aqueous extracts of the Bromus mixture, $H$. murinum, H. vulgare, M. rugosa, T. incarnatum, and P. tanacetifolia showed root length percentages close to $20 \%$ compared to the control at both doses. Similar values were observed for the extracts of F. arundinacea, M. sativa, and S. alba at $100 \%$ dose. Shoot elongation was as well restricted by almost all extracts (Figure 3C). The lowest percentages of shoot length (around 30\%) were observed with extracts of H. murinum, M. sativa, and T. incarnatum at $100 \%$ dose, with higher values (about 60\%) for the same species extracts at $50 \%$ doses. No differences in shoot elongation were observed compared to the control for the extracts of $F$. arundinacea and $V$. ciliata at $50 \%$ dose, whereas the extract of $S$. alba stimulated shoot growth.
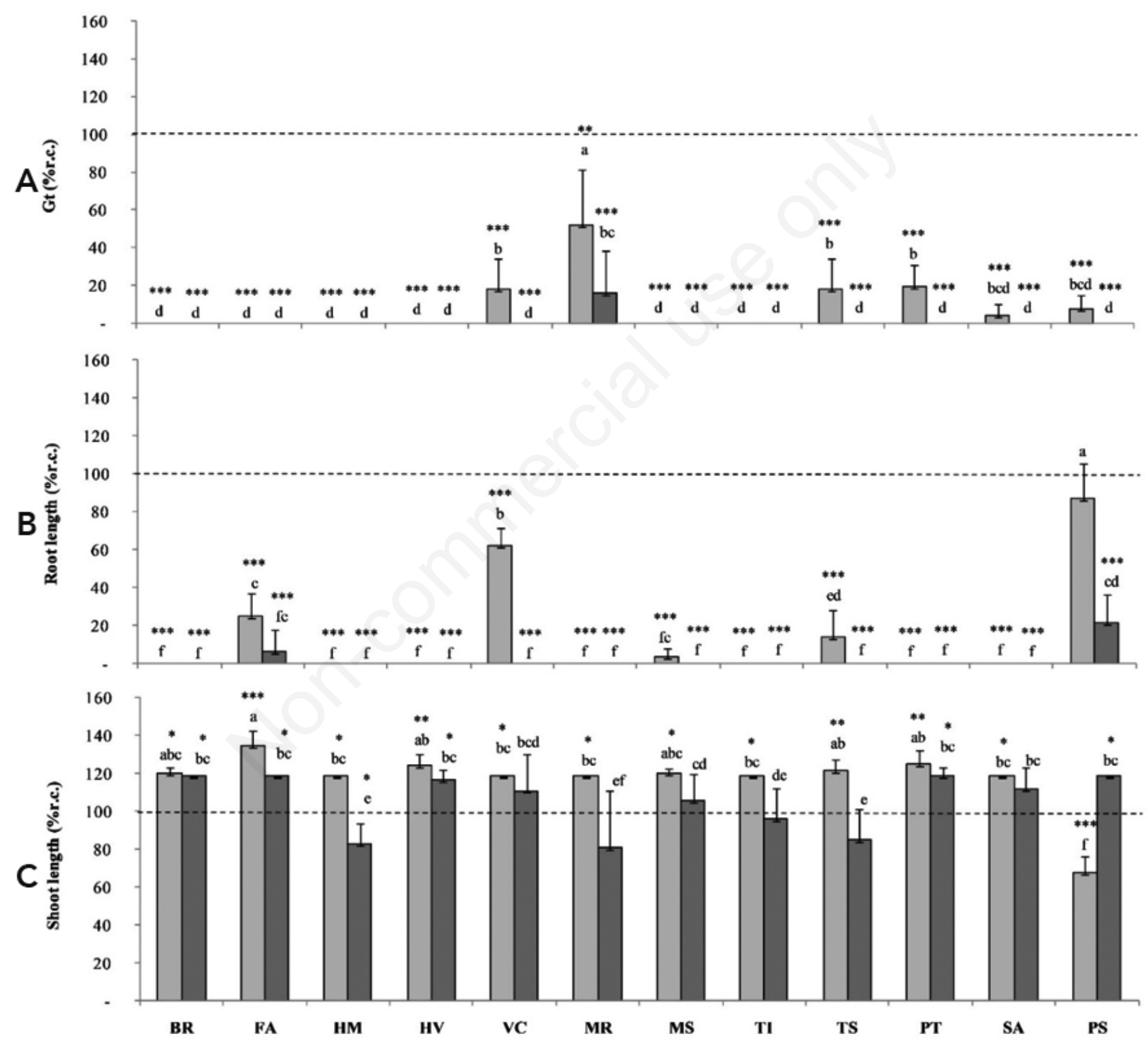

Figure 1. Effects of the aqueous extracts from the species assayed on the A) germination, B) root and, C) shoot growth of Conyza bonariensis at the doses of $50 \%(33.3 \mathrm{~g} / \mathrm{L})$ " and $100 \%(66.7 \mathrm{~g} / \mathrm{L})$ - . Gt, total percentage of germinated seeds; BR, Bromus mixture $(\mathrm{B}$. hordeaceus and B. rubens); FA, Festuca arundinacea; HM, Hordeum murinum; HV, H. vulgare; VC, Vulpia ciliata; MS, Medicago sativa; MR, M. rugosa; TS, Trifolium subterraneum; TI, T. incarnatum; PT, Phacelia tanacetifolia; SA, Sinapis alba; PS, Pinus sylvestris. Mean values are represented as percentages relative to the control (\% r.c.). Error bars represent standard deviation (SD). For each species, asterisks denote statistically significant differences with respect to control $\left(100 \%\right.$ dashed line) at $* P \leq 0.05,{ }^{* *} P \leq 0.01$, and $* * * \mathbf{P} \leq 0.001$ (independent samples $\mathbf{t}$-test). Mean values labelled with distinct letters denote statistically significant differences among different aqueous extracts at $\mathbf{P} \leq \mathbf{0 . 0 5}$ (ANOVA or Kruskal-Wallis $\boldsymbol{H}$ test and post hoc Waller-Duncan or Tamhane T2 test). 
Identification of phenolic compounds from the different assayed aqueous extracts

A total of 33 phenolic compounds (phenolic acids and flavonoids) were quantitatively and qualitatively identified by HPLC-DAD from the studied species aqueous extracts, with a maximum of 13 compounds for $H$. vulgare and a minimum of 6 compounds for Bromus mixture and P. tanacetifolia. The total quantity of compounds was significantly different among the species, from $33.52 \mu \mathrm{g} \cdot \mathrm{mL}^{-1}$ for $F$. arundinacea to $1571.76 \mu \mathrm{g} \cdot \mathrm{mL}^{-1}$ for $S$. alba (Table 2).

The phenolic profile of the Bromus mixture revealed the presence of two phenolic acids (protocatechuic acid and chlorogenic/caffeic derivative) and 4 flavonoids (luteolin derivative ' 1 ', '2' and ' 4 ', and apigenin derivative ' 2 '). Chlorogenic/caffeic derivative was the most abundant compound with $39.48 \%$ (Table 2). Seven compounds were identified in $F$. arundinacea extracts with six phenolic acids (protocatechuic, vanillic, $p$-hydroxybenzoic, $p$-coumaric, syringic, and ferulic acids) and one flavonoid (taxifolin derivative). Protocatechuic acid was the most abundant compound, with a share of $48.72 \%$ (Table 2). The phenolic profile of $H$. murinum extract revealed the presence of 7 phenolic acids (protocatechuic, $\quad$ vanillic, $\quad p$-hydroxybenzoic, $\quad p$ -
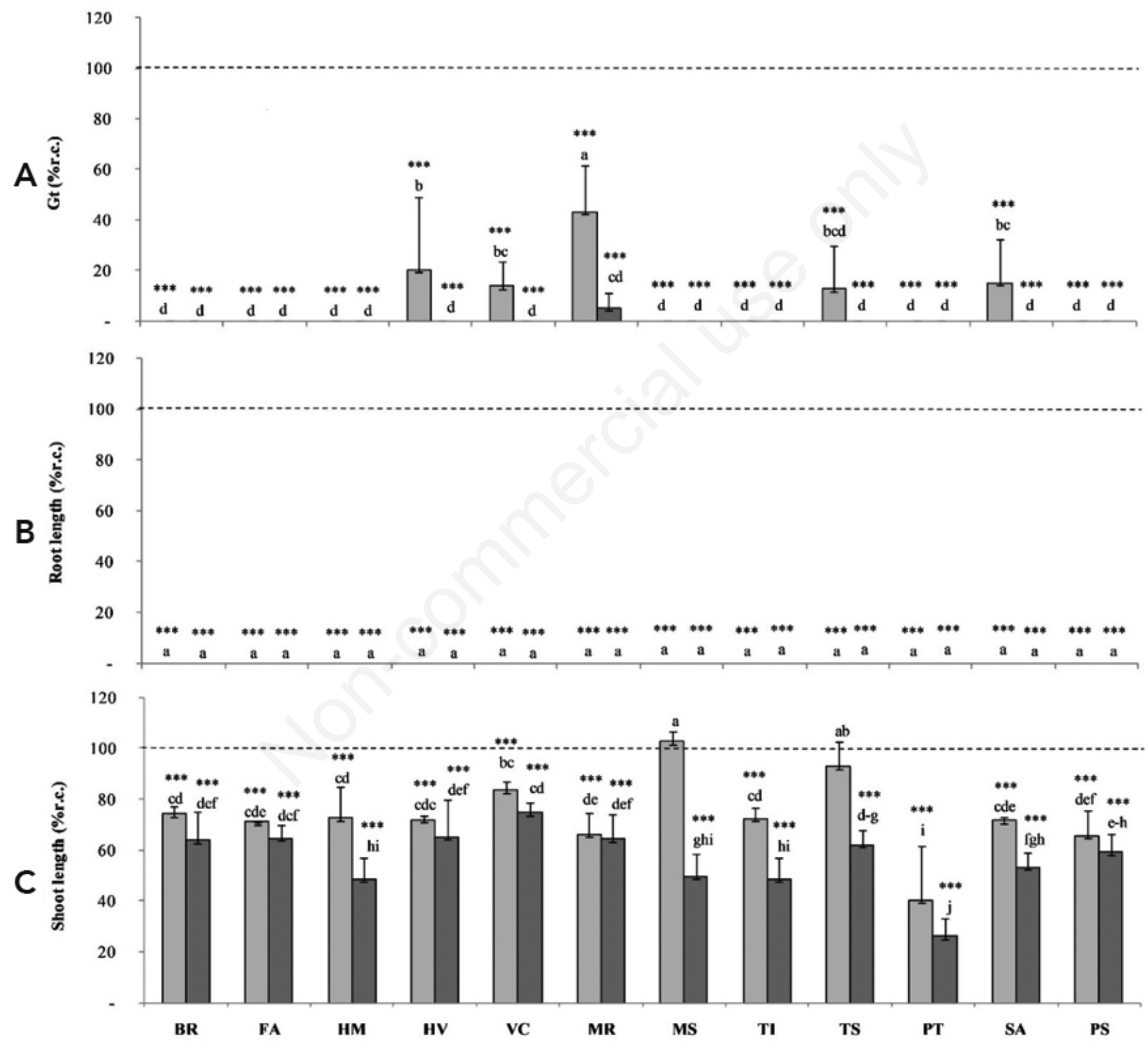

Figure 2. Effects of the aqueous extracts from the species assayed on the A) germination, B) root and, C) shoot growth of Aster squamatus at the doses of $50 \%(33.3 \mathrm{~g} / \mathrm{L})=$ and $100 \%(66.7 \mathrm{~g} / \mathrm{L}) \backsim$. Gt, total percentage of germinated seeds; BR, Bromus mixture $(B$. hordeaceus and B. rubens); FA, Festuca arundinacea; HM, Hordeum murinum; HV, H. vulgare; VC, Vulpia ciliata; MS, Medicago sativa; MR, M. rugosa; TS, Trifolium subterraneum; TI, T. incarnatum; PT, Phacelia tanacetifolia; SA, Sinapis alba; PS, Pinus sylvestris. Mean values are represented as percentages relative to the control (\% r.c.). Error bars represent standard deviation (SD). For each species, asterisks denote statistically significant differences with respect to control $(100 \%$ dashed line) at $* P \leq 0.05, * * P \leq 0.01$, and $* * * \mathbf{P} \leq \mathbf{0 . 0 0 1}$ (independent samples $\mathbf{t}$-test). Mean values labelled with distinct letters denote statistically significant differences among different aqueous extracts at $\mathbf{P} \leq \mathbf{0 . 0 5}$ (ANOVA or Kruskal-Wallis $\mathrm{H}$ test and post hoc Waller-Duncan or Tamhane T2 test). 
hydroxybenzaldehyde, $p$-coumaric, syringic, and ferulic acid) and five flavonoids (apigenin and two derivatives ' 1 ' and ' 2 ', ellagic acid and luteolin derivative ' 5 ') (Table 2). The most abundant compounds were apigenin derivative ' 2 ' and ' 1 ', with 187.84 $\mu \mathrm{g} \cdot \mathrm{mL}^{-1}$ and $150.18 \mu \mathrm{g} \cdot \mathrm{mL}^{-1}$, respectively. In $H$. vulgare aqueous extract, a total of 13 compounds were identified, six phenolic acids (protocatechuic, vanillic, $p$-hydroxybenzoic, $p$-coumaric, syringic, and ferulic acid) and seven flavonoids (luteolin derivative ' 1 ', ' 2 ', ' 3 ' and ' 5 ', apigenin, and two apigenin derivatives ' 2 ' and ' 3 ') (Table 2). As in H. murinum, the most abundant was apigenin derivative ' 2 ', with a $32.16 \%\left(54.60 \mu \mathrm{g} \cdot \mathrm{mL}^{-1}\right)$. In $V$. ciliata aqueous extract, nine compounds were identified, two phenolic acids (protocatechuic and vanillic acid) and seven flavonoids (luteolin derivative ' 1 ', '2' ' 3 ' and ' 5 ', apigenin derivative ' 2 ' and ' 3 ', and taxifolin derivative) (Table 2). The most abundant compound was protocatechuic acid $\left(23.97 \%, 16.60 \mu \mathrm{g} \cdot \mathrm{mL}^{-1}\right)$. Both in $M$. sativa and $M$. rugosa, eight compounds were identified. In $M$. sativa, 4 compounds were phenolic acids (vanillic, $p$-hydroxybenzoic, $p$ coumaric, and ferulic acid) and four flavonoids (luteolin and one derivative, kaempferol and apigenin). The most abundant compound was ferulic acid, with a value of $49.57 \mu \mathrm{g} \cdot \mathrm{mL}^{-1}$ (Table 2). In $M$. rugosa, three phenolic acids were identified (vanillic, $p$-coumaric,
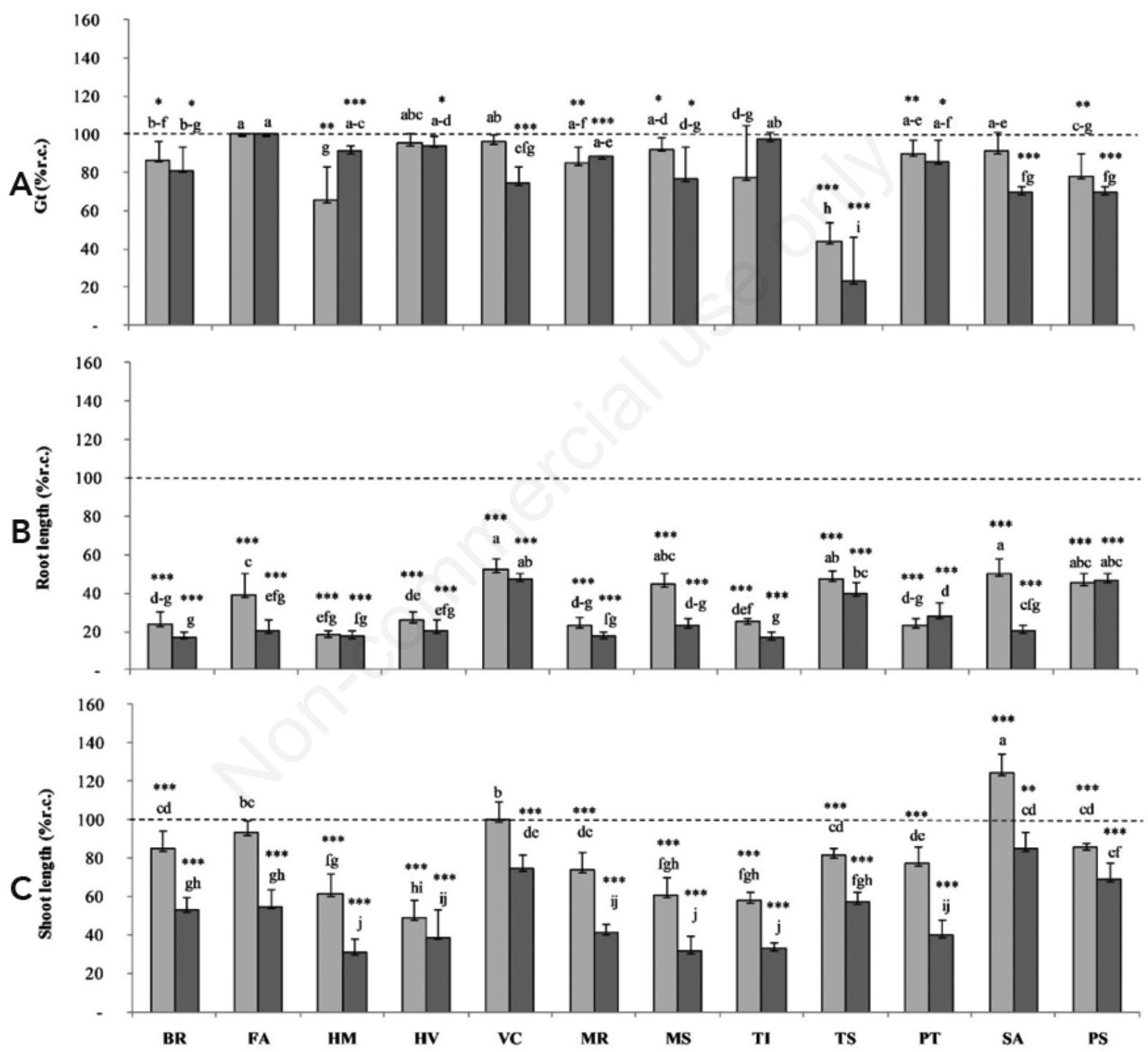

Figure 3. Effects of the aqueous extracts from the species assayed on the A) germination, B) root and, C) shoot growth of Bassia scoparia at the doses of $50 \%(33.3 \mathrm{~g} / \mathrm{L})=$ and $100 \%(66.7 \mathrm{~g} / \mathrm{L}) \backsim$. Gt, total percentage of germinated seeds; BR, Bromus mixture (B. hordeaceus and B. rubens); FA, Festuca arundinacea; HM, Hordeum murinum; HV, H. vulgare; VC, Vulpia ciliata; MS, Medicago sativa; MR, M. rugosa; TS, Trifolium subterraneum; TI, T. incarnatum; PT, Phacelia tanacetifolia; SA, Sinapis alba; PS, Pinus sylvestris. Mean values are represented as percentages relative to the control (\% r.c.). Error bars represent standard deviation (SD). For each species, asterisks denote statistically significant differences with respect to control $\left(100 \%\right.$ dashed line) at $* P \leq 0.05,{ }^{* *} P \leq 0.01$, and ${ }^{* * *} \mathrm{P} \leq 0.001$ (independent samples t-test). Mean values labelled with distinct letters denote statistically significant differences among different aqueous extracts at $\mathbf{P} \leq \mathbf{0 . 0 5}$ (ANOVA or Kruskal-Wallis $\mathrm{H}$ test and post hoc Waller-Duncan or Tamhane T2 test). 
and ferulic acid) and five flavonoids (ellagitannin ' 2 ', luteolin derivative ' 3 ' and ' 5 ', ellagic acid, and apigenin derivative ' 3 '). Luteolin derivative ' 5 ' was the most abundant compound in $M$. rugosa aqueous extract, representing $27.06 \%$ of the total (Table 2 ). The phenolic profile of $T$. subterraneum revealed ten compounds, six phenolic acids (protocatechuic, vanillic, $p$-hydroxybenzoic, caffeic, $p$-coumaric, and ferulic acid), and four flavonoids (taxifolin, naringenin, prunetin, and one prunetin derivative) being the only species with high amounts of prunetin, a prunetin derivative, and naringenin (Table 2). Trifolium incarnatum aqueous extracts yielded nine compounds: 4 phenolic compounds (protocatechuic, vanillic, $p$-hydroxybenzoic, and syringic acid), and five flavonoids (luteolin derivative ' 1 ', ' 2 ' and ' 5 ', and apigenin derivative ' 2 ' and ' 3 ' (Table 2 ). The most abundant compound was apigenin derivative ' 2 ' with $42.57 \%$. Only six compounds were identified in P. tanacetifolia, two phenolic acids ( $p$-hydroxybenzoic acid and chlorogenic/caffeic derivative), and four flavonoids (ellagitannin ' 1 ' and ' 2 ', eriodictyol and one luteolin derivative). Ellagitannin ' 1 ' was the most abundant compound, representing $60.94 \%$ of the identified (Table 2). Sinapis alba yielded nine compounds: 4 phenolic acids (vanillic, $p$ hydroxybenzoic acid, $p$-hydroxybenzaldehyde, and $p$-coumaric acid), and five flavonoids (ellagitannin ' 1 ' and '2', luteolin derivative '1', ellagic acid, and kaempferol derivative) (Table 2). Luteolin derivative ' 1 ' was the most abundant compound (40.64\%). Nine compounds were identified from the aqueous extracts of $P$. sylvestris: 8 phenolic acids (gallic, protocatechuic, vanillic, $p$ hydroxybenzoic, trans-cinnamic, $p$-coumaric, and ferulic acids, and vanillin), and one flavonoid (naringenin) (Table 2), the most abundant being vanillin $\left(52.57 \mu \mathrm{g} \mathrm{mL}^{-1}\right)$.

\section{Predicted involvement of phenolic compounds in the phytotoxicity of the aqueous extracts. Stepwise regression analyses}

Results of the stepwise regression analyses are summarized in Table 3. The concentrations of each phenolic compound present in each aqueous extract were entered as potential predictors of the phytotoxic effects measured on the agricultural weeds. The analysis displayed final models explaining 58 to $92 \%$ of the overall variance observed for the germination and early growth of $C$. bonariensis, A. squamatus, and B. scoparia, except for A. squamatus root length. For the last case, no significant predictive model was obtained.

Table 2. Phenolic acids and flavonoid compounds identified by HPLC-DAD from the aqueous extracts of Bromus mixture (BR), Festuca arundinacea (FA), Hordeum murinum (HM), H. vulgare (HV), Vulpia ciliata (VC), Medicago rugosa (MR), M. sativa (MS), Trifolium incarnatum (TI), T. subterraneum (TS), Phacelia tanacetifolia (PT), Sinapis alba (SA), and Pinus sylvestris (PS). Data expressed in $\mu \mathrm{g} \cdot \mathrm{mL}^{-1}$. RT: retention time $(\mathrm{min})$ on a reversed-phase Waters Nova-Pak C-18 column.

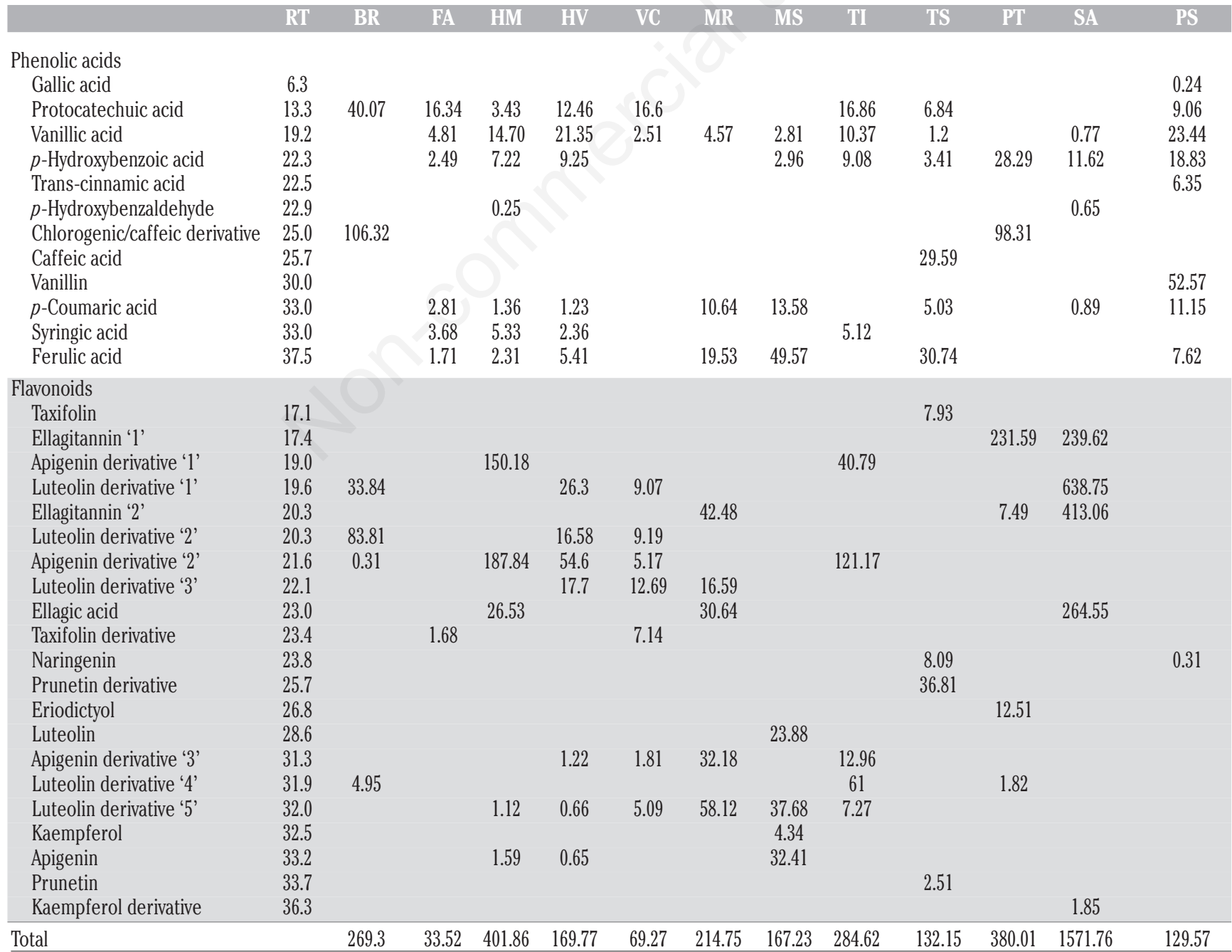


The phytotoxic effects on $C$. bonariensis germination were mainly explained by syringic, protocatechuic, and vanillic acids, besides apigenin, ellagitannin, and naringenin. None of the identified phenolic compounds predicted the inhibition of root length. The regression suggested that trans-cinnamic acid, taxifolin derivative, and prunetin, bearing positive coefficients, were the compounds that best predicted the root growth. Only gallic acid, entering with a negative coefficient, was identified as responsible for the shoot reduction $(\mathrm{P} \leq 0.001$; Table 3$)$.

In the case of $A$. squamatus, the phenolic compounds that could better explain the inhibitory effects on germination were $p$ hydroxybenzoic acid, protocatechuic acid, apigenin, and syringic acid $(\mathrm{P} \leq 0.001)$. Eriodictyol and $p$-coumaric acid also contributed negatively to shoot growth, while ferulic acid and taxifolin derivative increased the model predictive value with positive coefficients (Table 3). The flavonoids naringenin and apigenin derivatives were predicted as the principal determinants of the aqueous extract effects on $B$. scoparia germination. When including prunetin in the fit model, the prediction of germination in the regression analysis significantly improved. Apigenin and chlorogenic/caffeic derivatives, and the phenolic acids ellagic, syringic, and vanillic contributed negatively to root growth, while taxifolin derivative, $p$-hydroxybenzaldehyde, kaempferol derivative, and vanillin did positively (Table 3 ). For the shoot length, a total of seven compounds were predicted as responsible for the effects, kaempferol being the phenolic compound with the highest weight in the equation with a negative coefficient, followed by apigenin with a positive coefficient.

\section{Discussion}

The aqueous extracts of the assayed cover crop species showed in vitro inhibitory effects on the germination and root elongation of $C$. bonariensis and $A$. squamatus and lower but still significant phytotoxicity on B. scoparia. On the contrary, shoot elongation of $B$. scoparia was more sensitive than the other two weed species. After discarding a possible phytotoxic effect due to the main physicochemical properties of the aqueous extracts: i.e., $\mathrm{pH}<5$ or
$\mathrm{pH}>7$; EC $>2 \mathrm{dS} \mathrm{m}^{-1}$; and/or osmolarity $>0.1$ osmol kg-1 (ÁlvarezIglesias et al., 2014), the effects observed could be assigned to the allelochemicals present in the aqueous extracts. Furthermore, the phenolic acids and flavonoids identified by HPLC (both qualitatively and quantitatively) from the different plant aqueous extracts gave us an approximation of which could be released in the field since water is the natural solvent for these allelochemicals in nature. As far as we know, phenolic profiles of $H$. murinum, $V$. ciliata, M. rugosa, and the Bromus species used in the mixture ( $B$. hordeaceus and $B$. rubens) were reported in this work for the first time.

For the in vitro phytotoxicity bioassays, some of our results agree with those of Fujii (2001), who performed in vitro bioassays to study the allelopathic effect of different species usually sowed as cover crops. The author observed different percentages of root reduction of lettuce (Lactuca sativa L.) depending on the cover crop extracts, i.e., M. rugosa $(74 \%)>M$. sativa $(68 \%)>T$. incarnatum $(64 \%)>H$. vulgare $(62 \%)>F$. arundinacea $(55 \%)>$ Brassica alba (S. alba) $(53 \%)>$ T. subterraneum (30\%). Xuan et al. (2003) pointed out an allelopathic effect on rice exerted by $M$. sativa. In $S$. alba, Rice et al. (2007) observed in vitro a phytotoxic effect on lettuce seed emergence; meanwhile, Alcántara et al. (2011) indicated that $S$. alba cover crop residues reduced weed infestation at the field scale. Creamer et al. (1996) observed in field trials emergence suppression of Solanum ptycanthum Dun. by the cover crop residues of $T$. incarnatum and $H$. vulgare. The allelopathic potentials of T. incarnatum and Medicago lupulina L. (species related to M. rugosa) were reported by Price et al. (2008) in greenhouse trials. Also, Ipomoea lacunosa L. emergence and dry weight decreased after $T$. incarnatum, and $T$. subterraneum residues were incorporated into the soil (Scavo et al., 2020; Resuccia et al., 2020). Other authors have reported the allelopathic potential of $H$. vulgare (Baghestani et al., 1999; Bertholdsson, 2004, Chon and Kim, 2004) and its phytotoxic effects on Echinochloa crus-galli (L.) Beauv., Setaria verticillata (L.) Beauv., Veronica hederifolia L., or Papaver rhoeas L. in field experiments (Dhima et al., 2006, 2008).

Festuca arundinacea aqueous extract displayed high phytotoxicity in all bioassays except for $B$. scoparia seed germination. This cover crop species has been widely used in vineyards due to its perennial habit, controlling vine vigour and

Table 3. Predictor variables of the effects of the phenolic compounds of twelve aqueous plant extracts on the germination and early growth of three agricultural weeds, identified from best-fit models (stepwise regression).

$\begin{array}{llll}\text { Stepwise regression equation } & r^{2} & F & \text { df }\end{array}$

Conyza bonariensis

Germination $\quad-0.256$ syringic acid -0.455 protocatechuic acid - 1.462 apigenin - 0.398 ellagitannin -0.426 vanillic acid -0.737 naringenin +1.169 ferulic acid

Root length $\quad 0.825$ trans-cinnamic acid +0.614 taxifolin derivative +0.121 prunetin

Shoot length $\quad-0.922$ gallic acid

\begin{tabular}{|c|c|c|c|c|c|}
\hline $\begin{array}{l}\text { Aster squamatus } \\
\text { Germination } \\
\text { Root length } \\
\text { Shont lenoth }\end{array}$ & $\begin{array}{l}\text { - } 0.539 p \text {-hydroxybenzoic acid - } 0.518 \text { protocatechuic acid - } 0.454 \text { apigenin }-0.281 \text { syringic acid } \\
\text { n.p. }\end{array}$ & 0.618 & 10.027 & 4 & $* * *$ \\
\hline \multicolumn{6}{|l|}{ Bassia scoparia } \\
\hline $\begin{array}{l}\text { Germination } \\
\text { Root length }\end{array}$ & $\begin{array}{l}-5.452 \text { naringenin }-0.442 \text { apigenin derivatives }+4.771 \text { prunetin } \\
-0.237 \text { apigenin derivatives }-0.682 \text { chlorogenic/caffeic derivative }+0.134 \text { taxifolin } \\
\text { derivative }+1.074 p \text {-hydroxybenzaldehyde }\end{array}$ & 0.581 & 29.619 & 3 & $* * *$ \\
\hline Shoot length & $\begin{array}{l}-3.546 \text { ellagic acid }+2.612 \text { kaempferol derivative }-0.280 \text { syringic acid }-0.440 \text { vanillic acid }+0.303 \text { vanillin } \\
-2.852 \text { kaempferol derivative }+0.258 \text { taxifolin derivative }-0.920 \text { apigenin derivatives }-17.036 \\
\text { apigenin }+16.846 \text { kaempferol }+3.527 p \text {-hydroxybenzaldehyde }+0.191 \text { syringic acid }\end{array}$ & $\begin{array}{l}0.828 \\
0.868\end{array}$ & $\begin{array}{l}33.103 \\
60.194\end{array}$ & $\begin{array}{l}9 \\
7\end{array}$ & $\begin{array}{l}* * * \\
* * *\end{array}$ \\
\hline
\end{tabular}

variable), expressed in the regression equations in a positive (increase) or negative (decrease) effect. n.p., not predictive; Sig., significance of the predicted effect: ${ }^{* * *} \times \mathbf{P} 0.001$. 
reducing erosion, among other advantages. Our results add further evidence of the allelopathic potential of $F$. arundinacea, pointing out an extra agroecosystem service as a cover crop in vineyards. The phytotoxicity of $F$. arundinacea was previously reported by Bertoldi et al. (2012), who observed a 33\% reduction of in vitro lettuce germination, and effective control of Anagallis sp. or Sinapis sp. in field conditions when incorporating $F$. arundinacea cv. 'Villegeoise' biomass to the soil.

Some authors have studied $P$. tanacetifolia for weed control: Tursun et al. (2018) observed that $P$. tanacetifolia produced a high amount of biomass and was the most effective cover crop to suppress weeds at field scale (almost $75 \%$ of efficacy). On the contrary, Schappert et al. (2019) reported that this species could reach a high soil cover and biomass but weed control efficacy was lower than $40 \%$.

Other Bromus species have been used as cover crops with good weed control results, such as Bromus catharticus Vahl. cv. 'Samson' (Ibáñez et al., 2011). Serajchi et al. (2017), in greenhouse experiments, reported the allelopathic potential of Bromus porteri (Coult.) Nash against Taraxacum officinale Weber, Matricaria perforate Mérat, and Hordeum jubatum L.

The mulch of Pinus sp. has been widely adopted for weed suppression. However, Pinus sylvestris showed an intense phytotoxic effect in our study, especially on C. bonariensis and $A$. squamatus germination. Similar to our results, Bulut and Demir (2007) and Aklıbaşında et al. (2017) reported bioassays where $P$. sylvestris leaves showed dose-dependent inhibitory effects on seed germination and growth of different grass species, and Bielinis et al. (2019) observed similar effects on S. alba.

In general, root growth was more affected than shoot growth. Almost all extracts of the cover crops showed some stimulatory effects on shoot growth of $C$. bonariensis, especially when assayed at the lowest dose $(50 \%)$. Some allelopathic compounds can promote stimulatory growth effects when acting at low concentrations, displaying an effect known as 'hormesis' (e.g., Reigosa and Pazos-Malvido, 2007). Xuan et al. (2003) observed that the acidic fraction of $M$. sativa in low concentrations promoted shoot and root elongation of rice compared to control or high concentrations. Likewise, Pannacci et al. (2020) found that low concentrations of mugwort extract inhibited the germination and growth of Amaranthus retroflexus L. but stimulated the radicle, mesocotyl, and plant growth of maize. Thus, some plant extracts at low concentrations could also be exploited as plant biostimulants for agricultural purposes.

The different herbicidal potential of each plant species and/or the target physiological process affected depends on the richness and amounts of each phytotoxic compound and the mixture of compounds present in the plant extract (Inderjit, 1996; Puig et al., 2018; Pardo-Muras et al., 2020). Hence, the characterization of the chemical profile and the elucidation of which of these compounds might be responsible for the observed phytotoxic effects are essential to choosing the most suitable cover crop or mulch, or a combination of them, to control the weed seed bank in each case. Via HPLC-DAD, differences in the richness and abundance of phenolic compounds were observed among the different plant species' aqueous extracts.

Sinapis alba aqueous extract yielded the highest amounts of phenolic compounds, luteolin and ellagitannin derivatives being the most abundant. It is well known that $S$. alba seeds contain phenols, mainly phenolic acids (Kozlowska et al., 1983; Zielniok et al., 2016); however, only Hura et al. (2006) identified the phenolic profile of ethanolic extracts of $S$. alba plant material, characterized by the presence of trans-cinnamic, salicylic, ferulic, chlorogenic, protocatechuic, $p$-hydroxybenzoic, $p$-coumaric, and vanillic acids. The last three compounds were also detected in the chemical profile of our aqueous extract.

From a qualitative point of view, the aqueous extract of $H$. vulgare was the most diverse (13 identified compounds), rich in apigenin and luteolin derivatives. While that of H. murinum, characterized here for the first time, was the second richest aqueous extract, both qualitative and quantitatively, with high apigenin derivatives contents. Unlike $H$. murinum, the phenolic composition of $H$. vulgare is well known for its antioxidant, antifungal, and allelopathic properties (Ferreres et al., 2009; Piasecka et al., 2015; Deng et al., 2020; Horvat et al., 2020). Piasecka et al. (2015) reported 152 phenolic compounds in $H$. vulgare seedlings by organic solvent extraction, mostly flavonoids, among which some apigenin and luteolin derivatives were identified. However, barley's phytotoxic properties have usually been related to the synthesis of phenolic acids such as $p$-hydroxybenzoic, protocatechuic, vanillic, ferulic, and $p$-coumaric (Chon and Kim, 2004; Hura et al., 2006), also identified here.

The differences in polyphenol contents between chemical profiles from the literature and ours are consistent with using different solvents and extraction methods (Bajkacz et al., 2018; Deng et al., 2020), besides the particular phenotype expressed by different varieties in distinct environments and phenological stages. It is worth emphasizing that the compounds present in an aqueous plant extract are those prone to be released in the soil water by the decaying material, root exudates from the living cover crop, or decomposing mulch, thus having a potential allelopathic effect in nature. Then, the aqueous extract's phytotoxicity is the definitive symptom to consider the bioherbicide potential of particular plant material (Xuan et al., 2003).

Only six phenols were identified in the aqueous extracts of Bromus mixture and P. tanacetifolia, chlorogenic/caffeic derivatives being the most copious compounds in both species. No literature references were found concerning the phenolic profiles of $B$. hordeaceus and $B$. rubens, giving here the first report. For $P$. tanacetifolia, Bajkacz et al. (2018) identified a total of twelve phenolic acids and thirteen flavonoids in different solid-liquid extractions of flowers, leaves, stems, and roots; rutin and 4hydroxybenzoic acid were predominant in all investigated phacelia samples. The aqueous extract of $F$. arundinacea followed by $V$. ciliata showed the lowest total amounts of identified phenols. Bertoldi et al. (2012) revealed several classes of allelochemicals (pyrrolizidine alkaloids, flavonol glycosides, and flavonols) in $F$. arundinacea organic solvent extracts, but, unlike our case, the presence of phenolic acids was not determined. Buta and Spaulding (1989) reported phenolic allelochemicals (ferulic, $p$-coumaric, and abscisic acids) in leachates of tall fescue in high enough concentrations to cause growth inhibition.

In M. sativa and M. rugosa, similarities in the composition of their aqueous extracts were observed, with ferulic acid and one luteolin derivative as their primary compounds. According to the literature, this is the first phenolic profile of M. rugosa reported to date. For M. sativa, Bajkack et al. (2018) identified twenty-eight phenols using organic solvents; however, apigenin, luteolin and kaempferol, present in our water-soluble profile, were not determined. Chon and Kim (2002) identified nine phenolic acids (including $p$-coumaric and ferulic) in the aqueous extracts of the different vegetative parts of $M$. sativa, the leaves showing the highest phytotoxicity and richness of compounds. $P$ hydroxybenzoic, vanillic, $p$-coumaric, and ferulic acids were previously identified in $M$. sativa aqueous extracts by Xuan et al. (2003). 
Considerable differences were found in the phenolic composition between the aqueous extract of T. subterraneum and T. incarnatum. Trifolium subterraneum presented a higher concentration of phenolic acids (primary caffeic and ferulic) than flavonoids. $T$. incarnatum was characterized by a higher concentration of flavonoids (mainly one apigenin derivative). In the organic extracts of T. subterraneum, Tava et al. (2019) found only low amounts of phenolic compounds (glycosyl derivatives of caffeic acid and ferulic and coumaric acids), and Oleszek et al. (2007) described high concentrations of isoflavonoids and low concentration of phenolic acids and flavonoids. The last authors and Kolodziejczyk-Czepas et al. (2015) found shallow total contents of phenolic acids and high amounts of flavonoids -specifically, apigenin and luteolin derivatives (Zgórka, 2011) - in organic extracts of T. incarnatum. These findings are consistent with ours, whereas naringenin and prunetin had not been reported in $T$. subterraneum until now.

Pinus sylvestris aqueous extract was characterized by high contents and diversity in phenolic acids, being the only plant material with measurable quantities of gallic and trans-cinnamic acids and high vanillin levels. Dziedzinski et al. (2020) observed that $P$. sylvestris shoots aqueous extract was particularly rich in phenolic acids such as caffeic, ferulic, chlorogenic, 4hydroxybenzoic, $p$-coumaric, and gallic acids, all of them with reported phytotoxicity.

Finally, the stepwise regression analysis clarified the relationship between the cover crop or mulch phytotoxic activity and their allelochemical profiles by summarizing the variance of the effects of phenolic compounds identified in all the aqueous extracts. The regression indicated that the compounds involved in inhibiting $C$. bonariensis and A. aquamatus germination were the protocatechuic and syringic acids and apigenin. Noteworthy, the aqueous extracts containing high amounts and/or various of such compounds: Bromus sp., H. murinum, H. vulgare, $M$. sativa, and $T$. incarnatum, had comparable phytotoxic effects on the germination and root length of both target weeds. Ellagitannins (abundant in $M$. rugosa and even more in S. alba and P. tanacetifolia), the ubiquitous vanillic acid, and naringenin (only detected in T. subterraneum and P. sylvestris) were also predicted for explaining part of the inhibition of $C$. bonaerensis germination. On the other hand, Gallic and transcinnamic acids, exclusively detected in P. sylvestris, were evidenced to have counteracting effects on $C$. bonaerensis, the former inhibiting shoot growth and the latter stimulating root elongation. Previous studies reported that gallic acid prevented the growth of cress and Italian ryegrass seedlings (Hossen et al., 2020), as well as Leucaena leucocephala (Lam.) de Wit (Jose et al., 2016) and Phaseolus mungo L. (Li et al., 2010).

The quite ubiquitous $p$-hydroxybenzoic and $p$-coumaric acids also predicted inhibitory effects on $A$. squamatus germination and shoot growth, respectively. Apigenin, very abundant in $M$. sativa aqueous extract, and eriodyctiol, found only in P. tanacetifolia, were pointed out as responsible for inhibiting the germination and early shoot growth of $A$. squamatus. $P$-coumaric acid has been identified in various plants, and its allelopathic potential was demonstrated in several studies (Reigosa and Pazos-Malvino, 2007; Li et al., 2010; Pardo-Muras et al., 2020). Otherwise, Zhang et al. (2017) observed that eriodyctiol decreased the seed germination and seedling growth of Agrostis stolonifera L. and L. sativa.

The phytotoxicity of many of the mentioned phenolic compounds has been well recognized (Macías et al., 2003; Reigosa and Pazos-Malvino, 2007; Li et al., 2010). The fact that no specific compound was predictive for the inhibition of $A$. squamatus root growth suggests that many of the compounds, if not all, would contribute to the observed phytotoxicity, as has been argued by other authors (Blum, 1996; Reigosa et al., 1999). The same argumentation applies to $C$. bonariensis, for which the model that explained more than $92 \%$ of the variance for root elongation did not identify any sole compound as inhibitory, but only minority compounds in particular aqueous extracts as stimulatory. We do not discard that root length reduction could be due to other non-detected or nonanalysed compounds with phytotoxic activity (e.g., benzoxazinoids in Poaceae, and terpenes, alkaloids, or other previously reported phenolic compounds) in the aqueous extracts.

For the less sensitive weed species B. scoparia, the flavonoids naringenin, with very high relative weight, and to less extend apigenin derivatives were revealed as responsible for the germination inhibition. Naringenin was only detected in $T$. subterraneum and P. sylvestris to a minor concentration, the former being the only aqueous extract capable of inhibiting $B$. scoparia germination below $50 \%$, followed by $P$. sylvestris. The stepwise regression equation included nine predictor compounds (mainly apigenin and chlorogenic/caffeic derivative, ellagic, syringic, and vanillic acids) that explained more than $82 \%$ variance associated with root reduction. Masi et al. (2020) found that stoechanones A and $\mathrm{B}$ and $p$-coumaric acid methyl ester, derivatives from Lavandula stoechas L., inhibited seed germination of Amaranthus retroflexus, while caffeic acid methyl ester and apigenin did not significantly affect the germination of this weed. The flavonoids apigenin and kaempferol derivatives were also predicted to have reduced the shoot growth of B. scoparia. Cipollini et al. (2008) found that apigenin alone inhibited the germination of Arabidopsis thaliana (L.) Heynh seeds. There is evidence that apigenin and kaempferol derivatives from Cistus ladanifer $\mathrm{L}$. can reduce the growth rate of Rumex crispus L. (Chaves et al., 2001). Recently, Pardo-Muras et al. (2020) observed that naringenin reduced the root length of $A$. retroflexus, and ellagic acid and kaempferol inhibited the shoot growth in Digitaria sanguinalis (L.) Scop. only when applied at low concentrations.

Interestingly, syringic acid negatively affectedthe root length but positively the shoot length of $B$. scoparia; the opposite was observed with kaempferol derivatives. These effects might be explained by the specificity of target physiological processes of allelochemicals suggested in previous works (Inderjit et al., 2005; Hiradate, 2006). Therefore, from our results, the aqueous extracts' phytotoxicity was probably due to phenolic compounds' specificity and joint action and possibly the interactions among them and other non-detected or non-analysed compounds, both synergistic and antagonistic.

\section{Conclusions}

In vitro germination and early root growth of $C$. bonariensis and A. squamatus were almost entirely restricted by any of the twelve plants' aqueous extracts. Such finding supports the allelopathic potential of the species to be used as cover crops or mulch for weed control in vineyards, some of them evaluated here for the first time. The phenolic acids and flavonoids identified by HPLC-DAD (both qualitatively and quantitatively) from the different plant aqueous extracts gave us an approximation of those allelochemicals potentially released from the cover crops or mulches into the agricultural soil. The regression analysis selected some compounds responsible for the effects on $C$. bonariensis and A. squamatus, namely protocatechuic and syringic acids and apigenin, present in Bromus sp., H. murinum, H. vulgare, M. sativa, and T. incarnatum; 
ellagitannins, abundant in M. rugosa, S. alba, and P. tanacetifolia; the almost ubiquitous vanillic, $p$-hydroxybenzoic and $p$-coumaric acids; naringenin, present in T. subterraneum and P. sylvestris; gallic acid, exclusively detected in P. sylvestris; and eriodyctiol, found only in P. tanacetifolia. The participation of other non-detected or non-analysed compounds with phytotoxic activity should not be discarded.

Bassia scoparia germination was relatively much less sensitive to the extracts, except for T. subterraneum, for which the flavonoid naringenin was predicted to underlie its specific phytotoxicity. Otherwise, the early shoot growth of B. scoparia was more sensitive to the majority of the plant aqueous extracts than the other two weed species.

Of course, the potential effects on weeds of these cover crops and mulches in the field would depend on many interacting biotic and abiotic factors. The next necessary step would be to test these species for weed control in vineyards, at least those never used before as cover crops, to measure their weed suppression abilities (by both resource competition and allelopathy) and their stability through the seasons. However, knowing the phytotoxic nature of any cover crop or mulch a priori and the magnitude of their allelopathic potential on one or another target weed species would contribute to on-site decision-making.

\section{References}

Abad J, Marín D, Gonzaga Santesteban L, Cibriain JF, Sagüés A, 2020. Under-wine cover crops: impact on weed development, yield and grape composition. OENO One. 54:975-83.

Aklıbaşında M, Külekçi EA, Demir M, Bulut Y, 2017. The inhibiting effects of Scots pine (Pinus sylvestris) on germination ability and growth of some culture ryegrass species. J. Environ. Biol. 38:919-22.

Al-Alahmadi MJ, Mohammad K, 2007. Cardinal temperatures for germination of Kochia scoparia (L.). J. Arid Environ. 68:308-14.

Alcántara C, Pujadas A, Saavedra M, 2011. Management of Sinapis alba subsp. mairei winter cover crop residues for summer weed control in southern Spain. Crop Prot. 30:1239-44.

Álvarez-Iglesias L, Puig CG, Garabatos A, Reigosa MJ, Pedrol N, 2014. Vicia faba aqueous extracts and plant material can suppress weeds and enhance crops. Allelopathy J. 34:299.

Álvarez-Iglesias L, Puig CG, Revilla P, Reigosa MJ, Pedrol N, 2018. Faba as green manure for field weed control in maize. Weed Res. 58:437-49.

Baghestani A, Lemieux C, Leroux GD, Baziramakenga R, Simard RR, 1999. Determination of allelochemicals in spring cereal cultivars of different competitiveness. Weed Sci. 47:498-504.

Bajkacz S, Baranowska I, Buszewski B, Kowalski B, Ligor M, 2018. Determination of flavonoids and phenolic acids in plant materials using SLE-SPE-UHPLC-MS/MS method. Food Anal. Methods. 11:3563-75.

Bajwa AA, Sadia S, Ali HH, Jabran K, Peerzada AM, Chauhan BS, 2016. Biology and management of two important Conyza weeds: a global review. Environ. Sci. Pollut. Res. 23:24694-710.

Bertholdsson NO, 2004. Variation in allelopathic activity over 100 years of barley selection and breeding. Weed Res. 44:78-86.

Bertoldi C, De Leo M, Ercoli L, Braca A, 2012. Chemical profile of Festuca arundinacea extract showing allelochemical activity. Chemoecology 22:13-21.

Bielinis E, Kwiatkowski J, Boiko S, 2019. Identification of Pinus sylvestris clones with highest and lowest allelopathic potential.
Bal. For. 25:8.

Blum U, 1996. Allelopathic interactions involving phenolic acids. J. Nematol. 28:259.

Bulut Y, Demir M, 2007. The allelopathic effects of scots pine (Pinus sylvestris L.) leaf extracts on turf grass seed germination and seedling growth. Asian J. Chem. 19:3169-77.

Buta JG, Spaulding DW, 1989. Allelochemicals in tall fescueabscisic and phenolic acids. J. Chem. Ecol. 15:1629-36.

Cerdan O, Govers G, Le Bissonnais Y, Van Oost K, Poesen J, Saby N, Gobin A, Vacca A, Quinton J, Auerwald K, Klik A, Kwaad FJPM, 2010. Rates and spatial variations of soil erosion in Europe: A study based on erosion plot data. Geomorphology 122:167-77.

Chaves N, Sosa T, Escudero JC, 2001. Plant growth inhibiting flavonoids in exudate of Cistus ladanifer and in associated soils. J. Chem. Ecol. 27:623-31.

Chon SU, Kim YM, 2002. Biological activity and quantification of suspected allelochemicals from alfalfa plant parts. J. Agron. Crop Sci. 188:281-5.

Chon SU, Kim YM, 2004. Herbicidal potential and quantification of suspected allelochemicals from four grass crop extracts. J. Agron. Crop Sci. 190:145.

Cipollini D, Stevenson R, Enright S, Eyles A, Bonello P, 2008. Phenolic metabolites in leaves of the invasive shrub, Lonicera maackii, and their potential phytotoxic and anti-herbivore effects. J. Chem. Ecol. 34:144-52.

Creamer NG, Bennett MA, Strinner BR, Cardina J, Regnier EE, 1996. Mechanisms of weed suppression in cover crop-based production systems. Hort. Sci. 31:410-3.

De Prado R, Dominguez C, Tena M, 1989. Characterization of triazine- resistant biotypes of common lambsquarters (Chenopodium album), hairy fleabane (Conyza bonariensis) and yellow foxtail (Setaria glauca) found in Spain. Weed Sci.37:1-4.

Deng N, Zheng B, Li T, Liu RH, 2020. Assessment of the phenolic profiles, hypoglycemic activity, and molecular mechanism of different highland barley (Hordeum vulgare L.) varieties. Int. J. Mol. Sci. 21:1175.

Dhima KV, Vasilakoglou IB, Eleftherohorinos IG, Lithourgidis AS, 2006. Allelopathic potential of winter cereals and their cover crop mulch effect on grass weed suppression and corn development. Crop Sci. 46:345-52.

Dhima K, Vasilakoglou I, Lithourgidis A, Mecolari E, Keco R, Agolli XH, Eleftherohorinos I, 2008. Phytotoxicity of 10 winter barley varieties and their competitive ability against common poppy and ivy-leaved speedwell. Exp. Agric. 44:385.

Dziedzinski M, Kobus-Cisowska J, Szymanowska D, StuperSzablewska K, Baranowska M, 2020. Identification of polyphenols from coniferous shoots as natural antioxidants and antimicrobial compounds. Molecules. 25:3527.

Einhellig FA, 2004. Mode of allelochemical action of phenolic compounds. In: F.A. Macías, J.C.G. Galindo, J.M.G. Molinillo, H.G. Cutler (Eds.), Allelopathy: chemistry and mode of action of allelochemicals. CRC Press, Boca Raton, FL, USA, pp. 217-238.

Farooq M, Jabran K, Cheema Z, Wahid A, Siddique K, 2011. The role of allelopathy in agricultural pest management. Pest Manag. Sci. 67:493-506.

FFerreres F., Krskova Z, Goncalves RF, Valentao P, Pereira JA, Dusek J, Martin J, Andrade PB, 2009. Free water-soluble phenolics profiling in barley (Hordeum vulgare L.). J. Agric. Food Chem. 57:2405-9.

Friesen LF, Beckie HJ, Warwick SI, Van Acker RC, 2009. The biology of Canadian weeds. 138. Kochia scoparia (L.) Schrad. Can. J. Plant Sci. 89:141-67. 
Fujii Y, 2001. Screening and future exploitation of allelopathic plants as alternative herbicides with special reference to hairy vetch. J. Crop Prod. 4:257-75.

Garcia L, Celette F, Gary C, Ripoche A, Valdés-Gómez H, Metay A, 2018. Management of service crops for the provision of ecosystem services in vineyards: a review. Agr. Ecosys. Environ. 251:158-70.

Gómez J, Llewellyn C, Basch G, Sutton P, Dyson J, Jones C, 2011. The effects of cover crops and conventional tillage on soil and runoff loss in vineyards and olive groves in several Mediterranean countries. Soil Use Manag. 27:502-14.

Heap I, 2021. The international survey of herbicide resistant weeds; June 22. Available from: www.weedscience.org

Hiradate S, 2006. Strategies for searching bioactive compounds: Total activity vs. specific activity. Amer. Chem. Soc. Symp. Ser. 927:113-27.

Horvat D, Šimić G, Drezner G, Lalić A, Ledenčan T, Tucak M, Plavšić H, Andrić L, Zdunić Z, 2020. Phenolic acid profiles and antioxidant activity of major cereal crops. Antioxidants. 9:527.

Hossen K, Das KR, Okada S, Iwasaki A, Suenaga K, Kato-Noguchi $\mathrm{H}, 2020$. Allelopathic potential and active substances from Wedelia Chinensis (Osbeck). Foods. 9:1591.

Hura T, Dubert F, Dąbkowska T, Stupnicka-Rodzynkiewicz E, Stokłosa A, Lepiarczyk A, 2006. Quantitative analysis of phenolics in selected crop species and biological activity of these compounds evaluated by sensitivity of Echinochloa crusgalli. Acta Physiol. Plant. 28:537-45.

Hussain MI, Gonzalez L, Souto XC, Reigosa MJ, 2011. Ecophysiological responses of three native herbs to phytotoxic potential of invasive Acacia melanoxylon R.Br. Agroforest. Syst. 83:149-66.

Ibáñez S, 2015. Mantenimiento del suelo en el viñedo mediante cubiertas vegetales. Ed. Gobierno de la Rioja, pp. 167.

Ibáñez S, Perez JL, Peregrina F, Garcia-Escudero E, 2011. Utilización de cubiertas vegetales en viñedos de la D.O.Ca. Rioja (España). Bulletín de l'OIV. 84:347-60.

Inderjit, 1996. Plant phenolics in allelopathy. Botanical Rev. 62:186-202.

Inderjit, Weston LA, Duke SO, 2005. Challenges, achievements and opportunities in allelopathy research. J. Plant Interact. 1:69-81.

Jose CM, Brandão Torres LM, Torres MAMG, Shirasuna RT, Farias DA, dos Santos Jr. NA, Grombone-Guaratini MT, 2016. Phytotoxic effects of phenolic acids from Merostachys riedeliana, a native and overabundant Brazilian bamboo. Chemoecology. 26:235-46.

Kempen HM, Graf J, 1981. Weed seed production. Proceedings of the Western Society of Weed Science, 34:78-81.

Kolodziejczyk-Czepas J, Nowak P, Kowalska I, Stochmal A, 2015. Antioxidant action of six Trifolium species in blood platelet experimental system in vitro. Mol. Cell. Biochem. 410:229-37.

Kozlowska H, Rotkiewicz D, Zadernowski R, 1983. Phenolic acids in rapeseed and mustard. J. Am. Oil Chem. Soc. 60:1119-23.

Kruidhof HM, van Dam NM, Ritz C, Lotz LAP, Kropff MJ, Bastiaans L, 2014. Mechanical wounding under field conditions: A potential tool to increase the allelopathic inhibitory effect of cover crops on weeds? Eur. J. Agron. 52:229-36.

Kunz CH, Sturm DJ, Varnholt D, Walker F, Gerhards R, 2016. Allelopathic effects and weed suppressive ability of cover crops. Plant Soil Environ. 62:60-6.

Li ZH, Wang Q, Ruan X, Pan CD, Jiang DA, 2010. Phenolics and plant allelopathy. Molecules. 15:8933-52.

Macías FA, Galindo JC, Molinillo JM, (Eds.) 2003. Allelopathy: chemistry and mode of action of allelochemicals. CRC Press,
Boca Raton, FL, USA.

Masi M, Pannacci E, Santoro E, Zermane N, Superchi S, Evidente A, 2020. Stoechanones $a$ and $b$, phytotoxic copaane sesquiterpenoids isolated from Lavandula stoechas with potential herbicidal activity against Amaranthus retroflexus. J. Nat. Prod. 83:1658-65.

Mayer AM, Poljakoff-Mayber A, 1963. The germination of seeds. Pergamon Press, Oxford, UK, pp. 244.

Morlat R, Jacquet A, 2003. Grapevine root system and soil characteristics in a vineyard maintained long-term with or without interrow sward. Am. J. Enol. Viticult. 54:1-7.

Oerke E, 2006. Crop losses to pests. J. Agric. Sci. 144:31-43.

Oleszek W, Stochmal A, Janda B, 2007. Concentration of isoflavones and other phenolics in the aerial parts of Trifolium species. J. Agric. Food Chem. 55:8095-100.

Osipitan OA, 2016. Relative ecological fitness of glyphosateresistant Kochia from Western Kansas. Ph.D dissertation. Kansas State University, Manhattan, KS, USA, pp. 14-114.

Osipitan O, Dille J, Bagavathiannan M, Knezevic S, 2019. Modeling population dynamics of Kochia (Bassia scoparia) in response to diverse weed control options. Weed Sci. 67:57-67.

Osuna MD, Fischer AJ, De Prado R, 2003. Herbicide resistance in Aster squamatus conferred by less sensitive form of acetolactate synthase. Pest Manag. Sci. 59:1210-6.

Pannacci E, Masi M, Farneselli M, Tei F, 2020. Evaluation of Mugwort (Artemisia vulgaris L.) aqueous extract as a potential bioherbicide to control amaranthus retroflexus L. in maize. Agriculture 10:642.

Pardo-Muras M, Puig CG, Souto XC, Pedrol N, 2020. Water-soluble phenolic acids and flavonoids involved in the bioherbicidal potential of Ulex europaeus and Cytisus scoparius. S. Afr. J. Bot. 133:201-11.

Piasecka A, Sawikowska A, Krajewski P, Kachlicki P, 2015. Combined mass spectrometric and chromatographic methods for in-depth analysis of phenolic secondary metabolites in barley leaves. J. Mass Spectrom. 50:513-32.

Price AJ, Stoll ME, Bergtold JS, Arriaga FJ, Balkcom KS, Kornecki TS, Raper RL, 2008. Effect of cover crop extracts on cotton and radish radicle elongation. Commun. Biometry Crop Sci. 3:60-6.

Prosdocimi M, Cerdà A, Tarolli P, 2016. Soil water erosion on Mediterranean vineyards: a review. Catena 141:1-21.

Puig CG, Reigosa MJ, Valentão P, Andrade PB, Pedrol N, 2018. Unravelling the bioherbicide potential of Eucalyptus globulus Labill: Biochemistry and effects of its aqueous extract. PLoS One 13:e0192872.

Puig CG, Revilla P, Barreal ME, Reigosa MJ, Pedrol N, 2019. On the suitability of Eucalyptus globulus green manure for field weed control. Crop Prot. 121:57-65.

Recasens J, Valencia F, Montull JM, Taberner A, 2018. Malas hierbas problemáticas en viñedos con cubiertas vegetales y métodos químicos para su control. Vida Rural 448:48-58.

Reigosa MJ, Pazos-Malvido E, 2007. Phytotoxic effects of 21 plant secondary metabolites on Arabidopsis thaliana germination and root growth. J. Chem. Ecol. 33:1456-66.

Reigosa MJ, Souto XC, González L, 1999. Effect of phenolic compounds on the germination of six weeds species. Plant Growth Regul. 28:83-8.

Restuccia A, Scavo A, Lombardo S, Pandino G, Fontanazza S, Anastasi U, Abbate C, Mauromicale G, 2020. Long-term effect of cover crops on species abundance and diversity of weed flora. Plants 9:1506.

Rice A, Johnson-Maynard J, Thill D, Morra M, 2007. Vegetable crop emergence and weed control following amendment with 
different Brassicaceae seed meals. Renew. Agr. Food Syst. 22:204-12.

Šajna N, Kaligarič M, Ivajnšič D, 2014. Reproduction biology of an alien invasive plant: a case of drought-tolerant Aster squamatus on the Northern Adriatic Seacoast, Slovenia. In: S. Rannow, M. Neubert (Eds.), Managing protected areas in central and eastern Europe under climate change. Advances in Global Change Research, vol 58. Springer, Dordrecht, the Netherlands.

Savage D, Borger CP, Renton M, 2014. Orientation and speed of wind gusts causing abscission of wind-dispersed seeds influences dispersal distance. Funct. Ecol. 28:973-81.

Scavo A, Restuccia A, Lombardo S, Fontanazza S, Abbate C, Pandino G, Anastasi U, Onofri A, Mauromicale G, 2020. Improving soil health, weed management and nitrogen dynamics by Trifolium subterraneum cover cropping. Agron. Sustain. Dev. 40:1-12.

Schappert A, Schumacher M, Gerhards R, 2019. Weed control ability of single sown cover crops compared to species mixtures. Agronomy 9:294.

Serajchi M, Schellenberg MP, Lamb EG, 2017. The potential of seven native north American forage species to suppress weeds through allelopathy. Can. J. Plant Sci. 97:881-90.

Souto XC, Bolaño JC, González L, Santos XX, 2001. HPLC techniques-phenolics. In: Handbook of plant ecophysiology techniques. Springer, Dordrecht, the Netherlands, pp. 251-282.

Sturm DJ, Peteinatos G, Gerhards R, 2018. Contribution of allelopathic effects to the overall weed suppression by different cover crops. Weed Res. 58:331-7.

Tava A, Pecio L, Lo Scalzo R, Stochmal A, Pecetti L, 2019. Phenolic content and antioxidant activity in Trifolium germplasm from different environments. Molecules 24:298.

Tursun N, Iş1k D, Demir Z, Jabran K, 2018. Use of living, mowed, and soil-incorporated cover crops for weed control in apricot orchards. Agronomy 8:150.

Urbano J, Borrego A, Torres V, Leon J, Jimenez C, Dinelli G, Barnes J, 2007. Glyphosate-resistant Hairy Fleabane (Conyza bonariensis) in Spain. Weed Technol. 21:396-401.

Warren Raffa D, Antichi D, Carlesi S, Frasconi C, Marini S, Priori S, Bàrberi $\mathrm{P}, 2021$. Groundcover mulching in Mediterranean vineyards improves soil chemical, physical and biological health already in the short term. Agron. 11:787.

Weston LA, Duke SO, 2003. Weed and crop allelopathy. Crit. Rev. Plant Sci. 22:367-89.

Wu H, Walker S, Rolling MJ, Yuen DK, Robinson G, Werth J, 2007. Germination, persistence, and emergence of flaxleaf fleabane (Conyza bonariensis (L.) Cronquist). Weed Biol. Manag. 7:192-9.

Xuan TD, Tsuzuki E, Terao H, Matsuo M, Khanh TD, 2003. Correlation between growth inhibitory exhibition and suspected allelochemicals (phenolic compounds) in the extract of alfalfa (Medicago sativa L.). Plant Prod. Sci. 6:165-71.

Zgórka G, 2011. Studies on phytoestrogenic and nonphytoestrogenic compounds in Trifolium incarnatum L. and other clover species using pressurized liquid extraction and high-performance column liquid chromatography with photodiode-array and fluorescence detection. J. AOAC Int. 94:22-31.

Zhang HY, Qi SS, Dai ZC, Zhang M, Sun JF, Du DL, 2017. Allelopathic potential of flavonoids identified from invasive plant Conyza canadensis on Agrostis stolonifera and Lactuca sativa. Allelopathy J. 41:223-38.

Zielniok K, Szkoda K, Gajewska M, Wilczak J, 2016. Effect of biologically active substances present in water extracts of white mustard and coriander on antioxidant status and lipid peroxidation of mouse C 2 C 12 skeletal muscle cells. J. Anim. Physiol. Anim. Nutr. 100:988-1002. 